\title{
Prevalence of Human Hydatidosis in the Autonomous Area, Northern Iraq During 1987
}

Abdul L. Molan, Ph.D., Islam S. Saeed, M. Sc., Mahdi R. Baba, B. Sc., Arbil, Iraq

DOI: http://dx.doi.org/10.5915/22-2-13552

\begin{abstract}
In this study we describe 86 patients at the main hospitals of Arbil, Sulaimaniah and Dohuk provinces (the Autonomous Area) who in 1987 had surgically proven hydatid infection. Infection rate was higher in females than in males in the Sulaimaniah province, where as the opposite was true in Arbil and Dohuk provinces. Females were mostly housewives. Age ranged from 7 to 80 years, with the majority between $21-40$ years of age. Most organs of the body were involved, especially liver, lung, peritoneum, spleen and other organs. The organ most commonly affected was the liver, followed by the lungs. Those having single organ involvement accounted for $83.7 \%$ of patients, while $16.3 \%$ had multiple organ or site involvement by hydatid cysts.
\end{abstract}

Key words: Human hydatidosis, Autonomous Area, Iraq.

\begin{abstract}
Background
Hydatid disease is caused by the cystic larval stage of the cestodes Echinococcus granulosus and $E$. multilocularis. Although the latter is thought not to occur in Iraq, ${ }^{1,2}$ one case was reported in $1983 .{ }^{3}$ This disease is an important public health and economic problem as it affects both man and livestock and is found in varying degrees on every continent. ${ }^{*}$ Although the seriousness and prevalence of the disease in Iraq has been reported by many workers, ${ }^{1-3,5-10}$ the actual prevalence is still uncertain because these studies were carried out in only four of the eighteen provinces of Iraq. The present study was undertaken to difine the prevalence of ,human hydatidosis in the Autonomous Area, northern Iraq, during 1987.
\end{abstract}

\section{Materials and Methods}

The Autonomous Area has three main cities: Arbil

From Department of Biology, College of Education University of Salahaddin, Arbil, Iraq.

Reprint Requests: Dr. A. L. Molan

Department of Biology, College of Education

University of Salahaddin, Arbil, Iraq (population $=742,538)$ Dohuk (population $=$ 292,931 ) and Sulaimaniah (population $=292,513$ ).

We reviewed the records from January to December, 1987, in the main hospitals of Arbil, Dohuk and Sulaimaniah to identify patients who had surgically proven hydatidosis. The following data were collected for each patients: age, sex, address, date of surgery and organ(s) involved.

\section{Results}

In the Autonomous Area, 86 patients (46 females and 40 males) with hydatidosis underwent surgery during 1987. The geographical distribution shows wide variation among provinces. (Table 1) In Arbil, only 17 cases occurred $(2.3 / 100,000$ inhabitants), while in Dohuk province, the incidence was highest $(11.6 / 100,000$ inhabitants). Both sexes were nearly equally affected in each province. The age of the patients ranged from 7 to 80 years. The age group showing the highest incidence was 21-30 years in Arbil and Sulaimaniah, whereas in Dohuk province the incidence was highest in the $31-40$ years age group. (Table 2) Seventeen (10 females and 7 males, 19.8\%) patients were under age 21 years.

The recorded occupations are summarized in Table 3. Among females, housewives were the most frequently infected $(58.7 \%)$. The other patients were 
Table 1. Number of surgically treated cases of hydatid disease in the provinces of the Autonomous Area according to the sex and rates per 100,000 population.

\begin{tabular}{lcccc}
\hline Province & Males & Females & Total & $\begin{array}{c}\text { No. cases/ } \\
\text { 100,000 } \\
\text { Population }\end{array}$ \\
\hline Arbil & 10 & 7 & 17 & 2.3 \\
Dohuk & 18 & 16 & 34 & 11.6 \\
Sulaimaniah & 12 & 23 & 35 & 3.6 \\
Total & 40 & 46 & 86 & 4.4 \\
\hline
\end{tabular}

Table 2. Number of surgical cases of hydatid disease by age of patient at operation.

\begin{tabular}{crrrrrr}
\hline $\begin{array}{c}\text { Age at } \\
\text { Operation } \\
\text { (Years) }\end{array}$ & \multicolumn{2}{c}{ Arbil } & \multicolumn{2}{c}{ Dohuk } & \multicolumn{2}{c}{ Sulaimaniah } \\
\hline $1-10$ & 0 & 0.0 & 3 & 8.8 & 2 & 5.7 \\
$11-20$ & 1 & 5.9 & 5 & 14.7 & 6 & 17.1 \\
$21-30$ & 5 & 29.4 & 9 & 26.5 & 12 & 34.3 \\
$31-40$ & 4 & 23.5 & 10 & 29.4 & 6 & 17.1 \\
$41-50$ & 2 & 11.8 & 3 & 8.8 & 4 & 11.4 \\
$51-60$ & 3 & 17.7 & 4 & 11.8 & 3 & 8.6 \\
$61-70$ & 1 & 5.9 & 0 & 0 & 2 & 5.7 \\
$71-80$ & 1 & 5.9 & 0 & 0 & 0 & 0 \\
Total & 17 & 100 & 34 & 100 & 35 & 100 \\
& & & & & & \\
\hline
\end{tabular}

Table 3. Distribution of patients with hydatid cysts reported during 1987 according to occupation.

\begin{tabular}{lcccc}
\hline & \multicolumn{4}{c}{ Numbers of cases } \\
\cline { 2 - 5 } Occupation & Arbil & Dohuk & $\begin{array}{c}\text { Sulai- } \\
\text { mania }\end{array}$ & Total \\
\hline Housewife & 7 & 10 & 10 & 27 \\
Labourer & 5 & 5 & 12 & 12 \\
Student & - & 5 & 8 & 13 \\
Farmer & - & 5 & 2 & 7 \\
Pre-school & & & & \\
age children & - & 3 & 1 & 4 \\
Teacher & - & - & 1 & 1 \\
Retired & - & 2 & 1 & 3 \\
Soldier & - & 4 & - & 4 \\
Priest & 1 & - & - & 1 \\
Shopkeeper & 4 & - & - & 4 \\
Total & 17 & 34 & 35 & 86 \\
\hline
\end{tabular}

Table 4. Location of hydatid cysts among patients operated on in 1987.

\section{Province}

\begin{tabular}{lrrrr}
$\begin{array}{lrrr}\text { Organ } \\
\text { Involved }\end{array}$ & Arbil & Dohuk & $\begin{array}{c}\text { Sulai- } \\
\text { mania }\end{array}$ & Total \\
\hline Liver & 10 & 12 & 10 & 32 \\
Lung & 4 & 6 & 7 & 17 \\
Peritonem & 1 & 5 & 7 & 13 \\
Spleen & - & 1 & 1 & 2 \\
Brain & - & - & 1 & 1 \\
Uterus & - & 2 & 2 & 4 \\
Ovary & - & - & 1 & 1 \\
Kidney & 1 & - & - & 1 \\
Total & 17 & 26 & 29 & 72 \\
\hline
\end{tabular}

Table 5. Multiple organ involvement in surgical cases of hydatid disease in Automous Area during 1987.

\begin{tabular}{lccc}
\hline & \multicolumn{3}{c}{ No. of cases/Province } \\
\cline { 2 - 4 } Organ involved & Arbil & Dohuk & $\begin{array}{c}\text { Sulai- } \\
\text { mania }\end{array}$ \\
Liver and peritoneum & - & 1 & 2 \\
Liver and Lung & - & 3 & - \\
Liver and spleen & - & 1 & 1 \\
Lung and peritoneum & - & 3 & 1 \\
Lung and spleen & - & - & 1 \\
Uterus and ovary & - & - & 1 \\
Total & - & 8 & 6 \\
\hline
\end{tabular}

laborers ( 8 females and 14 males), farmers ( 2 females and 5 males), students (7 females and 6 males), preschool age children ( 2 females, and 2 males), soldiers ( 4 males), shopkeepers (4 males), retired ( 3 males), one male teacher and one priest.

Of the 86 patients, $72(83.7 \%$ ) had single organ involvement (Table 4$)$ and $14(16.3 \%)$ had multiple organ involvement. (Table 5) Liver, lung and peritoneum were the most common sites of pathology having single or multiple cysts. In fact 62 $(72.1 \%)$ patients harbored cysts in these three organs. (Table 4)

\section{Discussion}

This study indicates that hydatid disease is a major problem in the Autonomous Area. The overall incidence of the disease among all patients admitted to the hospitals of Arbil, Sulaimaniah and Dohuk provinces was $0.7 \%, 1.4 \%$ and $1.5 \%$, respectively. These rates, especialy in Sulaimaniah and Dohuk provinces, are higher than those reported in the previous studies for Iraq. ${ }^{7,8,11}$ 
The data from this study show that the highest rate of infection was among housewives, which is in agreement with the previous studies in Iraq. ${ }^{6,8,10,11}$ The higher rate of infection among housewives may be related to the fact that they are more closely associated with infection sources, such as infected dogs, infested soil or vegetables contaminated with the eggs of $E$. granulosus. Consequently, education efforts must begin with this group.

Although the value of the age specific rates is questionable, since the incubation period for hydatid disease is of variable duration, the present study shows that the highest infection rate was in patients aged 21-40 years. Similarly Hassoun and Al-Salihi ${ }^{6}$ reported that the majority of patients infected with hydatid disease in Iraq lie in the age group of 25-40 years. Al-Jboori ${ }^{\top}$ in Iraq, and El-Boulaqi and Taguri $^{12}$ in Libya found that the highest incidence of the disease was in the age group between 20 and 30 years.

The present investigation revealed that in $19.8 \%$ of cases, infection occurred in patients under the age of 21 years. Mahmoud ${ }^{8}$ reported that of 105 patients infected with hydatid disease at Mosul hospitals (northern Iraq) in $1979,19(18.1 \%)$ were children and youths aged between 6 and 17 years. In northern Africa hydatidosis is predominant in young adults. ${ }^{13}$ This may be related to the fact that the infections seen in adults began in childhood. ${ }^{13,14}$

The relative frequency of organ involvement confirms the predominance of liver and lung localizations observed in various countries in the world. ${ }^{13,15,16}$

These data do not represent the true picture of the prevalence of hydatidosis in this area because the majority of patients are asymptomatic and never seek medical advice. Many other patients escape detection because diagnostic facilities, particularly serology, are limited. Some of those that are diagnosed refuse any surgical intervention. However, surgical incidence rates remain the basic index for evaluation of the efficacy of control measures. ${ }^{16,17}$

\section{References}

1. Senekje HA, Beatti CP: The incidence of hydatid disease in Iraq. Trans Roy Soc Med Hyg 1940; 33:461-462.

2. Babero BB, Al-Dabbagh MA, Al-Saffar AS, Frozen MA: The zoonoses of animal parasites in Iraq. Ann Trop Med Parasit 1962;57:499-510.
3. Al-Attar HK: Alveolar hydatid disease of the liver: First case report from man in Iraq. Ann Trop Med Parasit 1983;77:595-597.

4. Abdulssalam M, Acha PN, Agosin M, Blood DB, Gemmel MA, Kagan IG, Kaplan MM, Rausch RL, Schwabe CW, Smyth JD, Yamashita J: Research needs in Echinicoccosis (Hydatidosis). 1968 Bull WHO;39:110-113.

5. Niazi $A D$ : Hydatidosis in Iraq. Bull End Dis 1974;15:37-50.

6. Hassoun AS, Al-Salihi M: Views on the epidemiology and control of hydatid disease in Iraq. Iraq Med J 1973;21:39-51.

7. Al-Jeboori T: Hydatid disease: A study of the records of the Medical City Hospital. J Fac Med Baghdad 1976;18:65-75.

8. Mahmoud SS: Studies on hydatid disease in Mosul, Iraq. M. Sc. Thesis, University of Mosul, Iraq.

9. Al-Sakkal MB: Human hydatid disease in Mosul, Iraq. Iraq Med J 1982;29:80-86.

10. Salih NE, Hakem MN, Mekhlef AF: The incidence of human hydatidosis in Mosul, Iraq. J Egypt Soc Parasit 1983;13:501-508.

11. Molan AL, Baban MR, Hammad NR: Human hydatid disease in Kirkuk, Iraq. J Egypt Soc Parasit 1988 (In press).

12. El-Bulaqi HA, Taguri S: Incidence of human hydatid disease in Eastern Libya. J Egypt Soc Parasit 1980;10:101-106.

13. Bohir A, Larouze B, Hamdi A, Letaiff R, Prazuck I, Dridi M, Eaudebout C, Rousset JJ, Jemmail M: Distribution of surgical hydatidosis in central Tunisia (1982-1985). Acta Tropica 1989;46:47-53.

14. Beard TC: Evidence that a hydatid cysts is seldom "as old as patient". 1978 Lancet ii, 30-32.

15. Purriel P, Schantz P, Beovide H, Mendoza G: Human echinococcosis (hydatidosis) in Uruguay: A comparison of indicies of morbidity and mortality 1962-1971. Bull WHO 49:395-402.

16. Karpathios T, Fretzayas A, Nicolaidou P, Papadellis F, Vasalos M, Tselentis J, Thomaidis Y, Matsaniotis N: Statistical aspects of hydatid disease in Greek adults. Am J Trop Hyg 34:124-128b.

17. WHO/FAO/UNEP: Guidelines for surveillance, prevention and control of echinococcosis hydatidosis. 1981 WHO/VPR/ 81;28, Geneva. 